\title{
Comparison of the Clinical Value of Complexed PSA and Total PSA in the Discrimination between Benign Prostatic Hyperplasia and Prostate Cancer
}

\author{
Michael Froehner ${ }^{\mathrm{a}}$ Oliver W. Hakenberg ${ }^{\mathrm{a}}$ Rainer Koch $^{\mathrm{b}}$ Uta Schmidt \\ Axel Meye ${ }^{\mathrm{a}}$ Manfred P. Wirth ${ }^{\mathrm{a}}$ \\ Departments of a Urology and bedical Statistics, University Hospital 'Carl Gustav Carus', \\ Technical University of Dresden, Dresden, Germany
}

\section{Key Words}

Prostate-specific antigen $\cdot$ Benign prostate hyperplasia $\cdot$ Prostate cancer $\cdot$ ROC analysis

\begin{abstract}
Background: To compare the clinical value of the measurement of complex and total PSA in the discrimination between benign prostatic hyperplasia (BPH) and prostate cancer. Methods: In serum samples collected from 166 men with histopathologically proven clinically localized prostate cancer and of 97 men with $\mathrm{BPH}$, total prostate-specific antigen (PSA), complexed PSA and the free to total PSA ratio were determined. The statistical analysis was done by the comparison of the receiver operator characteristic (ROC) curves. Results: The areas under the ROC curves were 0.776 for total PSA, 0.799 for complexed PSA (total PSA vs. cPSA: $p<0.0001$ ) and 0.812 for the free to total PSA ratio. With a cut-off of $3.0 \mathrm{ng} / \mathrm{ml}$ for complexed PSA, the sensitivity was $90 \%$, the specific-
\end{abstract}

Possible conflict of interest/source of funding:The Bayer Company provided the complexed PSA assay for testing purposes. ity $58 \%$, the positive and the negative predictive values 79 and $78 \%$, respectively. With a cut-off of $4.0 \mathrm{ng} / \mathrm{ml}$ for total PSA, the sensitivity was $87 \%$, the specificity $59 \%$, the positive and the negative predictive values were 78 and $72 \%$, respectively. Conclusions: There was a statistically significant advantage for complexed PSA compared to total PSA in the discrimination between BPH and prostate cancer. The difference was, however, small and its clinical relevance is questionable.

Copyright $(2006$ S. Karger AG, Basel

\section{Introduction}

Prostate-specific antigen (PSA) determination is of paramount importance in the diagnosis and management of prostate cancer [1]. Several studies suggested that the measurement of PSA bound to serum proteins (complexed PSA) might improve the performance of PSA testing in the discrimination between benign and malignant prostatic conditions [2-5]. The aim of this study was to investigate whether the substitution of total PSA testing by measurement of complexed PSA may represent an advantage in clinical practice.

\section{KARGER}

Fax +4161306 1234 E-Mail karger@karger.ch www.karger.com
Michael Froehner, MD

Department of Urology, University Hospital 'Carl Gustav Carus'

Technical University of Dresden, Fetscherstrasse 74, DE-01307 Dresden (Germany) Tel. +49 351458 2447, Fax +49 3514584333

E-Mail Michael.Froehner@uniklinikum-dresden.de 
Table 1. Sensitivity, specificity, positive and negative predictive value for different complexed (cPSA) and total PSA (tPSA) and free to total PSA ratio (\%fPSA) thresholds in the whole study population

\begin{tabular}{lllll}
\hline Threshold & $\begin{array}{l}\text { Sensi- } \\
\text { tivity, } \%\end{array}$ & $\begin{array}{l}\text { Speci- } \\
\text { ficity, } \%\end{array}$ & \multicolumn{2}{l}{ Predictive value, \% } \\
\cline { 5 - 5 } & & & positive & negative \\
\hline cPSA 2.0 ng/ml & 95 & 44 & 75 & 84 \\
tPSA 2.5 ng/ml & 95 & 44 & 75 & 84 \\
$\%$ fPSA 28\% & 95 & 29 & 70 & 78 \\
cPSA 3.0 ng/ml & 90 & 58 & 79 & 78 \\
tPSA 4.0 ng/ml & 87 & 59 & 78 & 72 \\
\hline
\end{tabular}

${ }^{1}$ Valid for a prevalence of $63 \%$.

Table 2. Sensitivity, specificity, positive and negative predictive value for different complexed (cPSA) and total PSA (tPSA) and free to total PSA ratio (\% fPSA) thresholds in the total PSA range of $2-10 \mathrm{ng} / \mathrm{ml}$

\begin{tabular}{|c|c|c|c|c|}
\hline \multirow[t]{2}{*}{ Threshold } & \multirow{2}{*}{$\begin{array}{l}\text { Sensi- } \\
\text { tivity, \% }\end{array}$} & \multirow{2}{*}{$\begin{array}{l}\text { Speci- } \\
\text { ficity, } \%\end{array}$} & \multicolumn{2}{|c|}{ Predictive value, $\% 1$} \\
\hline & & & positive & negative \\
\hline cPSA $2.0 \mathrm{ng} / \mathrm{ml}$ & 95 & 16 & 70 & 62 \\
\hline tPSA $2.5 \mathrm{ng} / \mathrm{ml}$ & 95 & 16 & 70 & 62 \\
\hline$\%$ fPSA $28 \%$ & 95 & 31 & 74 & 75 \\
\hline cPSA $3.0 \mathrm{ng} / \mathrm{ml}$ & 87 & 43 & 76 & 62 \\
\hline $\mathrm{tPSA} 4.0 \mathrm{ng} / \mathrm{ml}$ & 81 & 45 & 75 & 54 \\
\hline
\end{tabular}

${ }^{1}$ Valid for a prevalence of $68 \%$.

\section{Materials and Methods}

Serum samples were obtained from 166 men with histopathologically proven clinically localized prostate cancer prior to radical prostatectomy and of 97 men with benign prostatic hyperplasia (BPH) prior to transurethral or transvesical surgery of the prostate. The latter patients had no evidence of malignancy in their resection specimens. Patients with a history of neoadjuvant androgen deprivation were not included into this study. The mean age was 65 years (range 48-78 years) among the cancer patients and 69 years (range $45-84$ years $)$ in the BPH patients $(\mathrm{p}<0.0001)$. The serum samples were processed immediately after collection and stored no longer than $8 \mathrm{~h}$ at $4^{\circ} \mathrm{C}$ before being frozen at $-80^{\circ} \mathrm{C}$. In all samples, total PSA (Abbott AxSym Total PSA, Abbott, Wiesbaden, Germany), the free to total PSA ratio (Abbott AxSym Free PSA) and the complexed PSA (Bayer Diagnostics, Fernwald, Germany) were determined. The statistical analysis was done by the comparison of the receiver operator characteristic (ROC) curves [6]. p values are raw values.

\section{Results}

The mean value of total PSA was $10.6 \mathrm{ng} / \mathrm{ml}$ (range $0.2-61 \mathrm{ng} / \mathrm{ml}$ ) in the prostate cancer and $5.1 \mathrm{ng} / \mathrm{ml}$ (range $0.3-35 \mathrm{ng} / \mathrm{ml})$ in the BPH group $(\mathrm{p}<0.0001)$. The mean value of complexed PSA was $9.3 \mathrm{ng} / \mathrm{ml}$ (range $0.2-$ $59 \mathrm{ng} / \mathrm{ml}$ ) in the cancer patients and $4.0 \mathrm{ng} / \mathrm{ml}$ (range $0.2-27 \mathrm{ng} / \mathrm{ml})$ in BPH patients $(\mathrm{p}<0.0001)$. The mean free to total PSA ratio was $14 \%$ (range $2.5-38 \%$ ) in cancer patients and $23 \%$ (range 6.3-47\%) in the BPH patients $(\mathrm{p}<0.0001)$. The ROC curves for total and complexed PSA and for the free to total PSA ratio are shown in figure 1. The areas under the ROC curves (AUC) were 0.776 for total PSA, 0.799 for complexed PSA and 0.812 for the free to total PSA ratio. The ROC curves for total PSA and complexed PSA differed significantly (fig. 1; $\mathrm{p}<0.0001)$. There were no significant differences between the ROC curves for total PSA and the free to total PSA ratio $(p=0.07)$ and for complexed PSA and the free to total PSA ratio $(p=0.25)$. At a sensitivity level of $95 \%$, threshold values of $2.0 \mathrm{ng} / \mathrm{ml}$ for complexed PSA, $2.5 \mathrm{ng} /$ $\mathrm{ml}$ for total PSA and $10 \%$ for the free to total PSA ratio were obtained. The figures for sensitivity, specificity, positive and negative predictive values for the $95 \%$ thresholds and for cut-off-values of 3 and $4 \mathrm{ng} / \mathrm{ml}$ are given in table 1, corresponding figures for the total PSA grey zone of $2-10 \mathrm{ng} / \mathrm{ml}$ are shown in table 2 . In the total PSA grey zone between 2 and $10 \mathrm{ng} / \mathrm{ml}$, the following AUC values were obtained: 0.723 for complexed PSA, 0.673 for total PSA $(p<0.0001$ for the comparison of the ROC curves of total and complexed PSA) and 0.795 for the free to total PSA ratio $(p<0.01$ for the comparison of the ROC curves of total and of the free to total PSA ratio). The comparison between the ROC curves of complexed PSA and the free to total PSA ratio narrowly failed the significance level $(p=0.05)$. The ROC curves in the total PSA grey zone between 2 and $10 \mathrm{ng} / \mathrm{ml}$ are shown in figure 2.

\section{Discussion}

Complexed PSA has been suggested to be a superior initial test in the detection of prostate cancer [2-5]. The measurement of complexed PSA instead of total PSA has been found to be able to reduce the number of unnecessary biopsies $[5,7]$. Other authors, however, questioned the clinical relevance of the statistically detectable advantage of complexed PSA [8]. Patients with an elevated PSA referred for surgical treatment of BPH represent a com- 


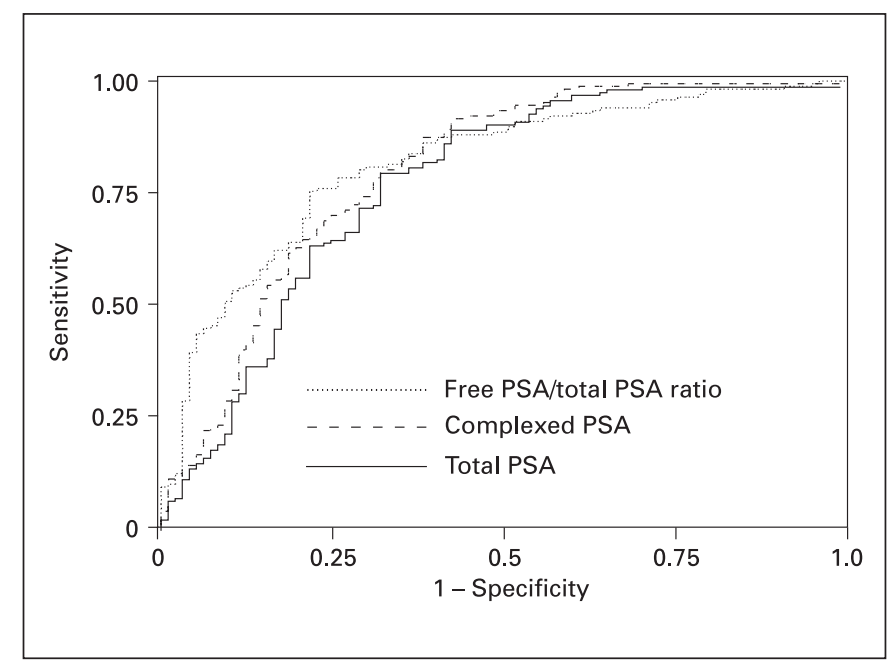

Fig. 1. Receiver operator characteristic curves for complexed PSA, total PSA and the free to total PSA ratio in the discrimination between benign prostate hyperplasia and prostate cancer in the whole study population.

mon problem in the setting of a hospital. In this population, it can be difficult to decide whether a prostate biopsy should precede surgical treatment of BPH. Therefore, we choose such patients for comparison with candidates for radical prostatectomy to evaluate the usefulness of the complexed PSA assay. Compared with multiple studies involving patients with positive and negative prostate biopsies [2, 4, 5, 8-15], in our study, the AUCs were higher for all PSA derivatives (indicating a better discrimination between benign and malignant prostatic conditions by the determination of PSA-related laboratory values). A selection effect might be a possible explanation for this phenomenon. It has been suggested that several ratios of PSA-related laboratory values may improve the discrimination between benign and malignant prostatic conditions $[2,11,13]$. The results were, however, inconsistent [11], and it is questionable whether one of the suggested ratios will gain general acceptance [16, 17]. Therefore, we dispensed with the analysis of ratios other than the free to total PSA ratio in this study. Compared to ROC curves, definite cut-off values are likely to be preferred in the clinical setting. Some authors report rather arbitrary cut-off values for complexed and total PSA (for instance $2.9 \mathrm{ng} / \mathrm{ml}$ for complexed PSA and $3.9 \mathrm{ng} / \mathrm{ml}$ for total PSA representing the 93rd sensitivity percentile [3] or 2.9 for complexed PSA and $4.0 \mathrm{ng} / \mathrm{ml}$ for total PSA representing the 90th sensitivity percentile in their studies [12]) or a broad range of possible cut-off val-

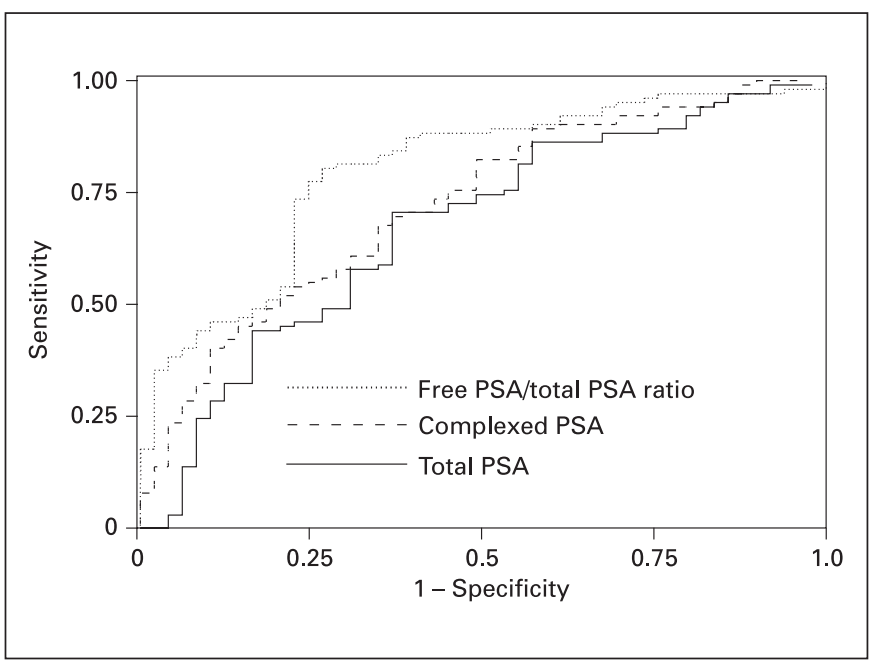

Fig. 2. Receiver operator characteristic curves for complexed PSA, total PSA and the free to total PSA ratio in the discrimination between benign prostate hyperplasia and prostate cancer in the total PSA range of $2-10 \mathrm{ng} / \mathrm{ml}$.

ues for complexed PSA [2]. Other authors used the 95th sensitivity percentile to define cut-off values and obtained differing results $[8,9]$. We considered two pairs of cut-off values suitable for clinical application, the $95 \%$ sensitivity threshold (in this study $2.0 \mathrm{ng} / \mathrm{ml}$ for complexed and $2.5 \mathrm{ng} / \mathrm{ml}$ for total PSA) and $3.0 \mathrm{ng} / \mathrm{ml}$ for complexed PSA and 4.0 for total PSA in agreement with values suggested by others [3,12] and with the most commonly used total PSA threshold of $4.0 \mathrm{ng} / \mathrm{ml}$. At these cut-offs, there was no appreciable difference in the performance of the complexed and total PSA tests in our study reflected by the associated specificity and positive and negative predictive values.

This study has several limitations. Since patients with symptomatic $\mathrm{BPH}$, partially at advanced age, were included as a cohort with a benign prostatic condition, the results may not necessarily apply to a screening population. Patients with BPH were in average four years older than those with prostate cancer. There was, however, only a weak and non-significant trend towards higher complexed and total PSA values with increasing age (data not shown). Furthermore, transrectal prostate biopsy is not entirely equivalent to transurethral (or transvesical) resection of the prostate in the verification or ruling out of prostate cancer. The described limitations are, however, not likely to interfere meaningfully with the interpretation of the study results. 
In summary, in the discrimination of $\mathrm{BPH}$ and prostate cancer, complexed PSA added little information to the conventional approach with determination of total PSA and the consideration of the free to total PSA ratio in cases of uncertainty. Even if complexed and total PSA were considered alone (and the free to total PSA ratio is ignored) and even if only the total PSA grey zone of 2-
$10 \mathrm{ng} / \mathrm{ml}$ was considered, the statistically significant advantage for complexed PSA was too small to be of clinical relevance in the setting of this study (tables 1,2).

\section{Acknowledgement}

To Romy Kranz and Andrea Lohse for technical assistance.

\section{References}

1 Hernandez J, Thompson IM: Prostate-specific antigen: a review of the validation of the most commonly used cancer biomarker. Cancer 2004;101:894-904

2 Partin AW, Brawer MK, Bartsch G, Horninger W, Taneja SS, Lepor H, Babaian R, Childs SJ, Stamey T, Fritsche HA, Sokoll L, Chan DW, Thiel RP, Cheli CD: Complexed prostate specific antigen improves specificity for prostate cancer detection: results of a prospective multicenter clinical trial. J Urol 2003;170:17871791.

3 Herrmann W, Stöckle M, Sand-Hill M, Hübner U, Herrmann M, Obeid R, Wullich B, Loch $\mathrm{T}$, Geisel J: The measurement of complexed prostate-specific antigen has a better performance than total prostate-specific antigen. Clin Chem Lab Med 2004;42:1051-1057.

4 Djavan B, Remzi M, Zlotta AR, Ravery V, Hammerer P, Reissigl A, Dobronski P, Kaisary A, Marberger M: Complexed prostate-specific antigen, complexed prostate-specific antigen density of total and transition zone, complexed/total prostate-specific antigen ratio, free-to-total prostate-specific antigen ratio, density of total and transition zone prostatespecific antigen: results of the prospective multicenter European trial. Urology 2002;60(suppl 1):4-9.

5 Sözen S, Eskicorapci S, Küpeli B, Irkilata L, Altinel M, Özer G, Uygur C, Alkibay T, Özen $\mathrm{H}$ : Complexed prostate specific antigen density is better than the other PSA derivatives for detection of prostate cancer in men with total PSA between 2.5 and $20 \mathrm{ng} / \mathrm{ml}$ : results of a Prospective Multicenter Study. Eur Urol 2005;47: 302-307.
6 DeLong R, DeLong D, Clarke-Pearson D: Comparing the areas under two or more correlated receiver operating characteristic curves: a nonparametric approach. Biometrics 1988; 44:837-845.

7 Parsons JK, Brawer MK, Cheli CD, Partin AW, Djavan R: Complexed prostate specific antigen (PSA) reduces unnecessary prostate biopsies in the $2.6-4.0 \mathrm{ng} / \mathrm{ml}$ range of total PSA. BJU Int 2004;94:47-50.

8 Martin B, Cheli CD, Lifsey D, Ward M, Pollard S, Jefferson L, Thiel RP, Rayford W: Complexed PSA performance for prostate cancer detection in an African-American population. Urology 2003;62:835-839.

9 Saika T, Tsushima T, Nasu Y, Kusaka N, Miyaji Y, Takamodo $\mathrm{H}$, Takeda $\mathrm{K}$, Uno S, Kumon $\mathrm{H}$, for the Okayama Urological Cancer Collaborative Group: Prostate specific antigen complexed to $\alpha 1$-antichymotrypsin in patients with intermediate prostate specific antigen levels. Cancer 2002;94:1685-1691.

10 Martinez M, Espana F, Royo M, Alapont JM Navarro S, Estelles A, Aznar J, Vera CD, Jimenez-Cruz JF: The proportion of prostatespecific antigen (PSA) complexed to $\alpha_{1}$-antichymotrypsin improves the discrimination between prostate cancer and benign prostatic hyperplasia in men with a total PSA of 10 $30 \mu \mathrm{g} / 1$. Clin Chem 2002;48:1251-1256.
11 Filella X, Truan D, Alcover J, Quinto L, Molina R, Luque P, Coca F, Ballesta AM: Comparison of several combinations of free, complexed, and total PSA in the diagnosis of prostate cancer in patients with urologic symptoms. Urology 2004;63:1100-1103.

12 McArdle PA, Pollock MA, Wallace AM, McMillan DC, Crooks JE, Underwood MA: Comparison of total, complexed and free prostatespecific antigens and their ratios in the detection of prostate cancer in a non-screened population. Ann Clin Biochem 2004;41:201-206.

13 Ozdal OL, Aprikian AG, Begin LR, Behlouli $\mathrm{H}$, Tanguay $\mathrm{S}$ : Comparative evaluation of various prostate specific antigen ratios for the early detection of prostate cancer. BJU Int 2004; 93:970-974.

14 Etzioni R, Falcon S, Gann PH, Kooperberg CL, Penson DF, Stampfer MJ: Prostate-specific antigen and free prostate-specific antigen in the early detection of prostate cancer: do combination tests improve detection? Cancer Epidemiol Biomarkers Prev 2004; 13:1640 1645.

15 Okihara K, Ukimura O, Nakamura T, Mizutani Y, Kawauchi A, Naya Y, Uchida M, Ogiwara T, Miki T: Can complexed prostate specific antigen enhance prostate cancer detection in Japanese men? Eur Urol 2004;46:57-64.

16 Djavan B: Editorial comment. Urology 2004; 63:1103-1104

17 Webber R: Editorial comment. BJU Int 2004; 93:974. 